A Kirkpatrick's double eye shield, as made by Messrs. Clement Clarke is tied in position over a cellophane apron cemented to the skin from the side of the nose to a point above the mid zygoma on the affected side. The apron should be about 8 inches long and 5 inches wide and cut with a suitable curve orbital skin, where it is stuck by Portex plic skin. The free end of the apron should have its edges cemented together for about 3 inches as a sleeve. This enables the drip from the eye to be caught in a suitable vessel. A glass dropper with short taper of suitable length is placed in one of the limbs of the cross aperture and strapped in position so that its tip is just over the caruncle, the other end is attached to a drip feed apparatus, timed for say 2 drops a minute. If the patient is unable to keep the eye open when the actual drop is falling he can be instructed to blink after the drop has fallen on the caruncle. This should ensure regular instillation while the patient is awake and co-operative, and relievè the nursing staff.

This device does not function while the patient is asleep. There are experimental indications that it may not be desirable to allow the drip to continue during the hours of sleep. It may be wiser to allow periods of rest and use the drip with fairly long intermissions. Should a continuous night drip be required and the upper lid be undamaged. or relatively free from swelling and distortion, another type of simple device will be found practicable.

An ordinary laboratory pipette is cut about $2 \frac{1}{2}$ inches from where the glass tube abruptly tapers. The cut end is bent in the small by-pass Bunsen flame to form a crook, the short limb of which is about $\frac{1}{4}$ inch long and parallel to the stem. A short length of small bore rubber tube such as Ryle's, or valve tubing, is threaded on to the crook.

This can be introduced under the inner end of the upper lid, and the pipette with its rubber tube attachment suitably fixed to brow and bed head by strapping.

\title{
THE END RESULTS OF OPERATION FOR DETACHMENT OF THE RETINA (With a follow up of fifty successful cases)* ${ }^{*}$
}

BY

\section{Montague L. Hine}

LONDON

SINCE the beginning of the War, I have had the opportunity, while in charge of an E.M.S. Ophthalmic Base, of operating on a considerable number of cases of detachment of the retina. I have

* Received for publication, June 15, 1944.

† Read at the Ophthalmological Section, Royal Society of Medicine, June 9, 1944. 
also been interested in following up the successful cases, and, though there is nothing very new to report, I felt it would be of interest to publish the results. Spectacular percentage successes have been reported in small groups of cases from time to time in the last few year and still more spectacular claims have been made for larger tolas, but none of these reports seem to have been made after sufficient period of time has elapsed since the operation.

In considering the results which follow, I feel that it should be remembered that, somewhat naturally, the Emergency Bases did not always get the pick of the cases, when the surgeon who first saw them had beds of his own available elsewhere. But, taken all in all, I think my figures could quite well apply to any unselected group of hospital cases. It will be indicated later that better results should be obtained from the "private" class of patient.

Up to the end of April, 1944, that is in four years and eight months, I have actually operated on, or been responsible for, 169 cases, one of whom died from an entirely fortuitous cause five days after operation, and so cannot be included in any list of success or failure. To get some finality of results, and to have a long enough period to follow up the cases, I have only made a full analysis of the first 120 patients, who were operated on by the end of November, 1942, with fifty successful results.

Now 50 cases out of 120 only gives a percentage of 41.66 per cent., and this seemed to be a rather poor return for all the trouble one took in the examination before operation, and the consequent planning of the latter. I then noticed that a very high percentage of bad risks came from one source, which supplied 49 of the patients with only 15 satisfactory results, a matter of 30.6 per cent. From all other sources I had had 71 cases, with 35 successes, i.e., 49.29 per cent. It is this latter figure, practically 50 per cent., which, I think can be taken as the right one for unselected hospital cases, done under satisfactory conditions. As a matter of interest, I found that fifteen of these 120 patients were, in the first place, sent to see me privately. Ten of them are included in the list of fifty successes; i.e., $66 \cdot 6$ per cent.

To show the importance of not publishing results too quickly or without sufficient follow up, out of the 120 cases, thirteen were sent out as satisfactory, with retina in place and a full field of vision, only to return at varying intervals of from three weeks to six months with the history of sudden loss of vision a day or so before, and with the retina redetached. Some two returned after three weeks, one returned after four weeks, two returned after five weeks, one returned after six weeks, three returned after eight weeks, one returned after ten weeks, two returned after twelve weeks, one returned after twenty-six weeks. 
On the other hand, two of the cases included amongst the list of fifty successes were sent out as failures, only to return, the one after eight months, the other after ten months, with retina in place and a full field. This fact was verified by two or three of my colleagues at the Royal Westminster Ophthalmic Hospital, so that I should not be solely responsible for the observations. Then, more recently, a third patient, operated on in May, 1943, and not included in the present series, came to my clinic five months after operation, to be transferred from the list of failures to the list of successes. I saw her again in February, 1944, and her vision was then $6 / 60$ in that eye.

Fifty Cases, seen or reported on after interval of :-

\begin{tabular}{|c|c|c|c|}
\hline Operation, September 13, 1939 & & & 4 years 4 months \\
\hline Operation, September 29, 1939 & $\ldots$ & $\ldots$ & 1 year 8 months \\
\hline Operation, Octobier 9, 1939 & $\ldots$ & ... & 2 years 6 months \\
\hline Operation, October 27, 1939 & $\ldots$ & $\ldots$ & 2 years 6 months \\
\hline Operation, November 1, 1939 & ... & ... & 1 year 6 months \\
\hline Operation, November 30, 1939 & ... & ... & 2 years 3 months \\
\hline Operation, April 30, $1940 \ldots$ & $\ldots$ & $\ldots$ & 2 years \\
\hline Operation, May 6, $1940 \quad \ldots$ & ... & & 2 years \\
\hline Operation, May 6, 1940 & $\ldots$ & & 3 years \\
\hline Operation, May $12,1940 \ldots$ & $\ldots$ & $\ldots$ & 1 year \\
\hline Operation, October 1,1940 & $\ldots$ & & 3 years 6 months \\
\hline Operation, October 1,1940 & $\therefore$ & ... & 3 years 5 months \\
\hline Operation, October 4, 1940 & ... & $\ldots$ & 1 year 6 months \\
\hline Operation, October 8, 1940 & $\ldots$ & & 1 year 6 months \\
\hline Operation, October 25,1940 & $\ldots$ & & 1 year 6 months \\
\hline Operation, October 25,1940 & ..' & & 3 years 2 months \\
\hline Operation, October 25,1940 & ... & & 1 year 6 months \\
\hline Operation, December 17, 1940 & $\ldots$ & & 4 months \\
\hline Operation, January 3,1941 & $\cdots$ & & 3 years \\
\hline Operation, January 11,1941 & ... & & 1 year 10 months \\
\hline Operation, January 11,1941 & & ... & 2 years 7 months \\
\hline Operation, March 23, 1941 & $\ldots$ & ... & 3 years 1 month \\
\hline Operation, April 1, 19+1 $\ldots$ & & & 4 months \\
\hline Operation, April 29, $1941 \ldots$ & $\ldots$ & & 1 year 11 months \\
\hline Operation, June 10,1941 (died) & ... & . & 5 months \\
\hline Operation, June 19, $1941 \ldots$ & $\cdots$ & & 1 year. 9 months \\
\hline Operation, July $1,1941 \quad \ldots$ & $\ldots$ & & 2 years \\
\hline Operation, July 22,1941 . & & & 8 months \\
\hline Operation, August 5, 1941 & ... & & 1 year 6 months \\
\hline Operation, August 5, 1941 & $\cdots$ & & 2 years 2 months \\
\hline Operation, September 2, 1941 & $\ldots$ & & 2 years 3 months \\
\hline Operation, September 23, 1941 & $\ldots$ & & 2 years 8 months \\
\hline Operation, September 30, 1941 & $\ldots$ & $\ldots$ & 1 year \\
\hline Operation, October 6, 1941 & & & 1 year 3 months \\
\hline Operation, November 11,1941 & & & 1 year 11 months \\
\hline Operation, December 9, 1941 & & & 6 months \\
\hline
\end{tabular}




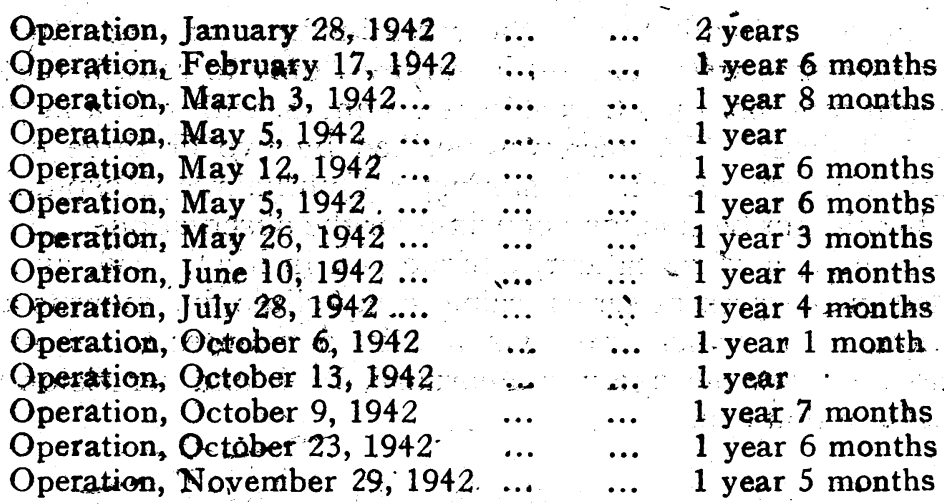

It will be seen, from reference to the list of the fifty successful cases, that all except five have been seen at least one year after operation, many much longer, and most on several occasions. One of the five died suddenly five months after operation, but was seen at Windsor with the operated eye quite satisfactory very shortly before death. The other four could not be traced when I started to gèt everyone to report after twelve months; but all had been satisfactory when seen, two four months, one six months, and the other eight months, after operation.

Two of the fifty cases were operated on by Mr. Gimblett, and two by Mr. Goldsmith while I was on holiday, while I was responsible for all the rest, as well as for all the noting and the follow up.

Three of the successful cases were operated on by electrolysis, in the very early days when we had no available diathermy unit, and the history of one of these over four years from operation will be given later.

Most of the rest had surface diathermy with Weve's applicator; with current varying from 110-120 milliamps, followed by diathermic puncture and removal of as-much sub-retinal fluid as possible with a " sucker." Keeler's technician was in charge of the apparatus, which arrangement I have always considered very satisfactory. Some of the disinsertions were however done with Lindner's $\frac{1}{2} \mathrm{~mm}$. perforating point with a small base to give additional surface 'reaction, using a current of 60 milliamps. This gives more localised reaction near the ciliary region, and small discrete reactions which are readily visible if the retina is not ballooned.

By succèssfui result one implies a complete reattachment of the retina, with full peripheral field, save where this is encroached upon by the operation area. Restoration of good, visual acuity is, naturally, a different matter, and depends on the degree of injury caused to the fovea by the detachment, or on the prior visual acuity 
POSITION OF HOLES, ETC., IN SUCCESSFUL CASES. RIGHT

LEFT

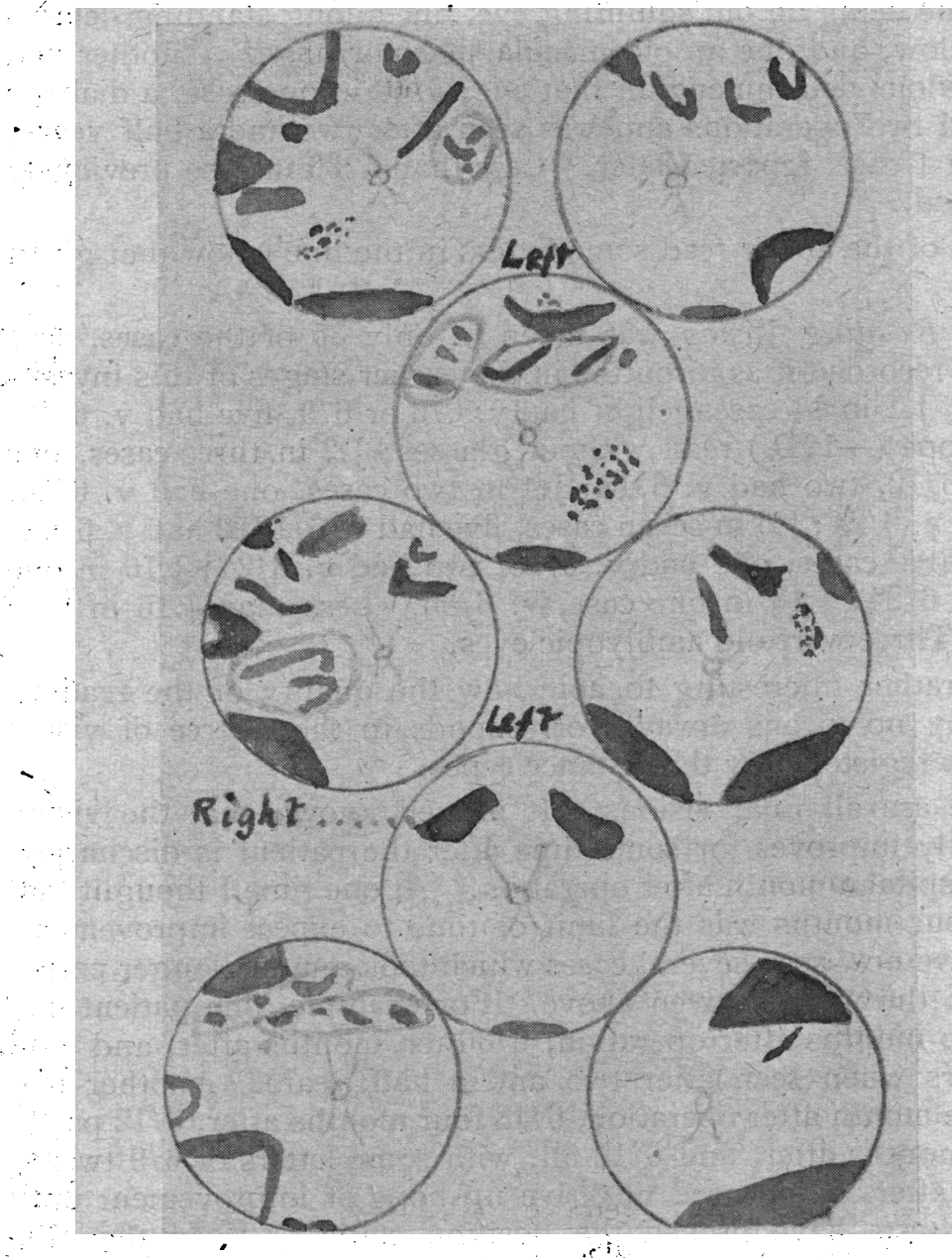

The six ringed holes were multiple. Otherwise each hole represents a separate case. Qne of the 50 cases had no hole or dis-insertion. There were 26 right eyes ; 23 left eyes; one left eye with no hole.

of the eye. One of my very contented patients, happy to regain his field of vision in an amblyopic right eye, actually had visual acuity of less than $1 / 60$.

Final Vision in the fifty cases was $-6 / 6$ in three cases; all of whom were originally seen privately; $6 / 9$ in five cases, two of whom were originally seen privately; $6 / 12$ in six cases; $6 / 18$ in ten cases; $6 / 24$ in eight cases; $6 / 36$ in nine cases; $6 / 60$ in six 
cases, one being an old squinting eye, one a long standing detachment below, and one an old macular haemorrhage. Another had had previous detachments in that eye; $3 / 60$ in one case, a diabetic who had two operations and was seen after two-and-a half years; $1 \frac{1}{2} / 60$ in 1 case, reported later. Less than $1 / 60$ in case previously mentioned.

Many of the above read some letters in the line below that given above.

Final Reading Vision. was taken in only 35 of the cases, as I had not recorded it as a routine in the earlier stages of this investigation. J.1 in 14 cases, eight had v: $6 / 6$ or $6 / 9$, five had v. $6 / 12$, one myope (-12D.) read without glasses; J.2 in three cases, one had v. $6 / 12$, two had v. $6 / 18 ;$ J.4 in two cases, one had v. $6 / 18$, one had v. $6 / 24$; J.6 in seven cases, five had v. $6 / 18,2$ had v. $6 / 24$; $\mathrm{J} .8$ in three cases, one had v. $6 / 18$, two had v. $6 / 24 ; \mathrm{J} .10$ in one case, v. $6 / 24 ; \mathrm{J} .16$ in one case, v. 6/36. Less than J.16 in four cases. Three were old amblyopic eyes.

It is rather interesting to note how the quality of the reading vision by no means always corresponds to the degree of visual acuity as registered by the distance types.

These are all final visions. It is well known that the vision frequently improves for some time after the patient is discharged from hospital a month after operation. At one time.I thought that about four months was the limit of time to expect improvement, but I have now seen several cases which took a much longer-period to attain the visions given above. For example, one patient had $6 / 60$ two months after operation, $6 / 36$ ten months after, and $6 / 18$ all letters when seen after two and a half years. Another had $6 / 36$ one month after operation, $6 / 18$ four months after, $6 / 12$ partly twelve months after, and 6/12 all, with some letters of $6 / 9$ twenty months after. One need not give up hope of improvement until interval tests have proved the position static. Even then the reading vision may go on improving though the visual acuity for distance has remained stationary over a period.

Of this-series of 120 cases, twenty had secondary operation. I have not had much success with this, and I believe that this is the general experience. But three of these cases are included amongst the fifty successes. Two had entirely fresh holes in a retina detached on the opposite side of the globe from the original detachment, and only one was re-done over, or adjacent to, the original operation area. If the original tear is well surrounded by reaction, further operation, apart from the finding of fresh holes, holds out little chance of success. Fresh tears appearing near the edge of the reaction area give an equally bad prognosis. 
Thirteen of the 120 cases had had previous detachment in the other eye, which was blind, that is 10.8 per cent. Some had had operation which was unsuccessful. In seven cases, which are included amongst the fifty successes, the result was very satisfactory; the other six were failures, in spite of secondary operation. I have subsequently had several more cases of this type. The fact that bilateral detachment is so relatively frequent is, I think, an added reason for advising operation for this condition when the other eye is a good one, save in the very unpromising cases.

- Four of the 120 cases were aphakic. Three of them had had discission in childhood; the other had had extraction for'senile cataract three or four years previously: Two of them had no visible hole or disinsertion. None of them was successful. I have, however, had a more recent case, operated on thirty-one years previously by Devereux Marshall when aged 11, whom I operated -on when aged 42, on July 6, 1943, and last saw in April, 1944, just nine months after operation. He had vision $6 / 36$, and a full field. In his case I had found a small hole in the retina down and out.

Myopic cases numbered forty-eight or 40 per cent. Of these seventeen were successful. There were:-Under $-6 \mathrm{D}$. nineteen cases-successful, 9, i.e., $47 \cdot 36$ per cent; -6D. to -12D. twenty cases-successful 8, i.e., 40 per cent.; over -12D. nine casessuccessful 0 .

Traumatic cases, with definite history of recent or more remote injury to the eye, numbered seventeen, or 13.83 per cent. Of these only nine were successful, but few of the unsuccessful cases were straightforward. One had had previous magnet extraction; two had enormoùs rents of long standing, and another had myopia averaging $-13 \mathrm{D}$. with two large parallel tears on the temporal side. Still another had come a lengthy and tedious journey from Crete, via Suez, Durban, and Liverpool, with stops at each, after being bombed and shipwrecked during the evacuation. He had a large disinsertion down and out, but also two small splits in the retina just external to the macula.

Multiple holes were present in 18 cases. Of these six, or 33.3 per cent., were successful.

Localised " moth-eaten areas" seem to hàve a good prognosis. There were three cases and all were successful.

No hole or disinsertion could be found in six cases, but four of these were the aphakic eyes mentioned above. This again proves how rare are the cases with no visible tear if the eye is thoroughly examined. Of the other two cases one was successful. She was seen two years and five months after operation.

I thought it might be interesting to compare the successful and 
unsuccessful cases in various age groups in an equal number of patients. I found as follows :-

\begin{tabular}{rrrrrrr} 
Age up to 20 & \multicolumn{2}{c}{ Successful } & 7 & \multicolumn{2}{c}{ Unsuccessful } & 4 \\
$20-30$ & $\ldots$ & $\ldots$ & 2 & $\ldots$ & $\ldots$ & 7 \\
$30-40$ & $\ldots$ & $\ldots$ & 8 & $\ldots$ & $\ldots$ & 5 \\
$40-50$ & $\ldots$ & $\ldots$ & 14 & $\ldots$ & $\ldots$ & 10 \\
$50-60$ & $\ldots$ & $\ldots$ & 12 & $\ldots$ & $\ldots$ & 17 \\
$-\quad$ over 60 & $\ldots$ & $\ldots$ & 7 & $\ldots$ & $\ldots$ & 7
\end{tabular}

If one divides the cases into two main groups, the under 40 and the over 40, it will be seen that the number of successtul cases in each group is practically identical with that of the unsuccessful. It is not age, in itself, which determines the prognosis.

The oldest successful cases in the present series were aged 66 years. But in November, 1943, I operated on a very well preserved man of 73 years with good result. I recently heard from $\mathrm{Mr}$. Aynsley in Bournemouth that he was still satisfactory.

The youngest patient was aged 9 years, and his case is reported later.

The detachment of longest standing successfully operated on in this series was in a boy aged 13 years. Two and a quarter years previously, in July, 1939, he had aimed a catapult at his left eye instead of away from it, and soon noticed the sight in that eye was misty. Before anything was done about it he was evacuated from London, and was not seen till October, 1941. He had retina detached to disc level with a big disinsertion down and out. On February 1, 1943, he had vision $6 / 36$ and J.8, with good field of vision.

But in August, 1943, I operated on a boy aged 15: years, with a history of direct trauma to the right eye over three years previously, with defective vision in that eye of same duration. He had not been seen before he came up from South Wales to visit his sister in London in 1943. He had a big disinsertion below. He now has only 6/60 vision, but his field is quite full and retina in place. I saw him and showed him to colleagues six months after operation.

In both cases projection of light was good over the detached area prior to operation. Both cases were traumatic in origin and both occurred in young lads.

I worked out the position of the tears in the fifty successful cases and in a corresponding number of unselected unsuccessful cases. I had to come to the conclusion that the chances of success are quite independent of position, but depend on the various other factors. The results were as follows :- 
End Results of Operation for Detachiment of Retina

\begin{tabular}{|c|c|c|}
\hline Upper half & Successful 30 & Unsuccessful 23 \\
\hline Equatorial & $\begin{array}{lll}\ldots & \ldots & 3\end{array}$ & $\begin{array}{lll}\ldots & \ldots & 6\end{array}$ \\
\hline Lower half & $\ldots \quad \ldots, 16$ & $\ldots$ \\
\hline & $\begin{array}{l}\text { (11 disinsertions } \\
2 \text { tiny holes.) }\end{array}$ & (3 disinsertions:) \\
\hline No visible tear & $\begin{array}{llll}\cdots & & \ldots & 1\end{array}$ & (2 aphakic.) \\
\hline
\end{tabular}

Of the straightforward cases there is nothing to say which is not already well known, except that I am still further convinced that only careful examinations, several times repeated while the patient is getting used to his, or her, surroundings in hospital for two or three days, at least, prior to operation, will give the best results and save a lot of time on the operating table. The operator must plan exactly where he will place his first electrode, and then check up on its pósition before making further applications, which should need little rechecking if he keeps his picture in mind. I always have one stuck on the wall during operation, with the measurements and meridians I have previously planned. On two or three occasions, by such simple methods, I have been able to do four cases in one morning, and, at any rate ón one occasion, October 25, 1940, three of the cases were successful and are. included in this series.

While one has put the average chance of success at 50 per cent., it certainly is not fair to the operator for other surgeons to put it as high as that in cases of extensive retinal degeneration, aphakia, multiple holes and large rents. In no selected group of cases should it be put higher than 75 per cent. in my opinion, as a few of the eyes which look very good risks altimately prove unsatisfactory. All the same, some of the cases which are included amongst the fifty successful ones seem to point the moral that there are few patients who should not be given the chance of operation if they are willing to take it. From this view point a few of the more remarkable histories should prove interesting.

The first is that of the youngest patient previously mentioned. $\mathrm{He}$ was certainly a most unfavourable case. He was a boy of nine years, with a mother blind from bilateral retinal detachment. His father was a German-Jewish doctor from Frankfort-on-Maine. At the age of five his right retina became detached and the eye blind. In January, 1940, he had a detachment in left eye, and was operated on by Weve in Utrecht in March, 1940, by barrage right down the temporal periphery and, later on, an injection of 2 per cent. pepsin into the vitreous, in an heroic attempt to dissolve vitreous bands. He got away from Holland just in time, before the invasion. His sight récovered sufficiently to let him get about and attend a small village school in this country, but 
must have been very poor. In December, 1940, it suddenly failed again. I saw him for Mr. Cole Marshall and took him into my base. There was a large disinsertion down and in, but there were also a number of congenital bands in the vitreous, forming a sort of framework, as well as a fold of retina, which may or may not have been congenital, or may have been due to injection into vitreous, running down and out from the nasat side of the disc. Weve's barrage was readily visible all down the extreme temporal periphery.

Very unexpectedly operation was successful, and the retina held for three years, as confirmed by several inspections by myself and the late St. Clair Roberts. Central vision was only $1 \frac{1}{2} / 60$, and he only read the Snellen 6 metre type at half a metre, but he was delighted with this, which he said was at least as good as after his first operation, and with his full field of vision,- with which he could not only walk, but run, about. He had obviously never known what good vision was. He was then sent to the Blind College at Worcester, and this was a wise step. Unfortunately, just three years after operation he had a fresh detachment and operation was unavailing. I have kept him on the list of successes, as I had set the standard at one year and he had lasted for three.

Another patient was a man aged 42 years. In 1936 , he also had lost the sight of his right eye from detachment, which had unsuccessful operation. In 1937 he had detachment in the left eye and end vision of $6 / 12$, after much perseverance and three operations by Gerald Penman. In September, 1940, his vision failed again in his left eye, and a fresh detachment, with three small, somewhat doubtful holes, was seen through a very hazy vitreous in the upper nasal quadrant.

After operation the opacity in the vitreous was much increased, and, after four weeks, he could distinguish nothing but light from dark. We kept him in for two months and the vitreous cleared considerably. He could then see $6 / 60$ with his glasses, which were $-12 \mathrm{D}$. He is the case whose vision took over two years to improve to $6 / 18$ and J.1 without glasses. The end result in his case far exceeded our expectations when his previous history was taken into account.

Another very unpromising case was a woman, aged 41 years, who is one of the three, previously mentioned, who had successful secondary operation. She was almost stone-deaf, with old I.K. in both eyes, and corrected vision ( $-6 \mathrm{D}$.) in - left eye of 6/36. She had extensive old peripheral choroiditis in both eyes. In January, 1942, she had a detachment in the right eye, with a peripheral tear below, with a hole in a tongue of retina attached 
to the ciliary region. Operation was on February 17, 1942. On March 16 visign was $6 / 60$ and retina flat. On April 20. she knocked her right eye against a chest of drawers and vision again failed. She was found to have a fresh detachment above, with a small horse-shoe tear about 2 "o'clock." Further diathermy. proved successful, and, when I last saw her in August, 1943, her vision was 6/24 and J.6.

One could report other cases which I have found of consider- able interest, but, finally, I will mention one who was treated by electrolysis, and was the first detachment operated on at the base. She was aged 52 years, when, in August, 1939, she had a detachment in her left eye, which was approximately -12D. myopic. It was her worst eye, and vision had never been more than $6 / 12$. There was a ballooned detachment up and out, with a rather large rectangular tear. Two months after operation vision was $6 / 24$ in that eye, and field was full. On January 7, 1943, she slipped and knocked her left temple on the floor. She had a small subconjunctival ecchymosis and a haemorrhage in the left macular area. Vision was less than $1 / 60$ but her field was full. I saw her twelve months later and her vision was again 6/24 with full field. Which record may well make us think, now that electrolysis is so much out of favour!

To sum up, this paper reports the results obtained from operation on 120 cases of detachment of the retina, and from a follow up of 'fifty successful cases. ' It is an attempt to give accurate details of cases watched for a sufficient period of time, and not a claim to spectacular performance. The results seem to agree very closely with the careful assessment made by Sir Stewart DukeEilder in his text-book of ophthalmology.

\section{ANNOTATION}

\section{Deficiencies in diet and Night-Blindness}

An early reference to our heading appears in Science (Bangalore), June, 1944, over the signature of W. R. Aykroyd of the Nutrition Research Laboratories, I.R.F.A., Coønoor, India. This author has described night-blindness among Newfoundland fishermen living on a diet deficient in vitamin $\mathrm{A}$, and says that the fishermen treated themselves by taking cod-liver oil, cod and seal liver, hen's and gull's livers, and "by such means cured themselves to their own satisfaction within 24 to 48 hours." But Aykroyd's most interesting item is an extract from "Narrative of a Journey through the 